\title{
AZT Myopathy and HIV-1 Polymyositis: One Disease or Two?
}

\author{
Kimberley Walsh, Kathy Kaye, Bart Demaerschalk, Sarah Stewart, Jeff Crukley, \\ Robert Hammond
}

\begin{abstract}
Purpose: This paper discusses the association between inflammatory and mitochondrial pathologies in patients with HIV-1/AIDS treated with zidovudine (AZT). Methods: We present the clinical and pathological details of a 52-year-old HIV-1 positive male who presented with progressive muscle weakness. We also review the current literature and address the debated pathogenesis of the inflammatory pathology. Results: Muscle biopsy revealed evidence of both HIV-1 polymyositis and AZT myopathy. Six months after initiation of corticosteroid therapy and discontinuation of AZT, the patient's symptoms had greatly improved. The biopsy was repeated to show that both pathologies had resolved. Conclusions: The perceived overlap in the pathological spectra of HIV-1 polymyositis and AZT myopathy has produced some debate on causation and treatment. Unfortunately, there have been very few reports where a repeat biopsy following a drug washout period confirmed resolution of the pathology. Furthermore, affected patients have not been treated in a uniform fashion. Whether this represents one disease or two remains uncertain. The clinical relevance of this issue lies in the potential for harm from the unnecessary use of corticosteroids. This question may be best addressed by a randomized clinical trial.
\end{abstract}

RÉSUMÉ: Myopathie à l'AZT et polymyosite à VIH-1: une ou deux maladies? Objectif: Cet article discute de l'association de pathologies inflammatoires et mitochondriales chez des patients atteints du VIH-1/SIDA qui sont traités par la zidovudine (AZT). Méthodes: Nous présentons les observations cliniques et anatomopathologiques à propos d'un patient de 52 ans, VIH-1 positif, qui a consulté pour faiblesse musculaire progressive. Nous revoyons également la littérature et la pathogenèse de la pathologie inflammatoire. Résultats: La biopsie musculaire a montré des signes de polymyosite à VIH-1 et de myopathie à l'AZT. Six mois après avoir commencé la corticothérapie et avoir cessé l'AZT, les symptômes du patient s'étaient améliorés considérablement. Une nouvelle biopsie a montré que les signes des deux pathologies étaient disparus. Conclusions: Le chevauchement des spectres anatomopathologiques de la polymyosite à VIH-1 et de la myopathie à l'AZT a engendré une controverse sur l'étiologie et le traitement. Malheureusement, il existe peu de cas rapportés où des biopsies avant et après le retrait du médicament ont confirmé la résolution des signes anatomopathologiques. De plus, les patients atteints n'ont pas tous été traités de la même façon. On ne sait pas s'il s'agit d'une ou de deux maladies. La pertinence clinique de cette question est liée au préjudice potentiel causé par la prise de corticostéroïdes. Un essai clinique randomisé serait la meilleure façon de répondre à cette question.

Can. J. Neurol. Sci. 2002; 29: 390-393

Infection with HIV-1 is associated with a variety of central and peripheral nervous system diseases. Although many are due to opportunistic infections and neoplasms many others are putatively mediated directly or indirectly (through immune dysfunction or toxin production) by HIV-1 itself. Prime examples of the latter are the HIV-1 associated dementia complex ${ }^{1,2}$ and a distal symmetric polyneuropathy. ${ }^{3-5}$

Myopathy in the setting of HIV-1 infection is commonly due to HIV-1 polymyositis and zidovudine (AZT) effect. ${ }^{6-16}$ Hallmarks of HIV-1 polymyositis include symmetrical proximal muscle weakness, increased creatine kinase (CK) levels, and the presence of inflammation, necrosis and phagocytosis in muscle biopsy material. ${ }^{8}$ Creatine kinase levels are typically elevated. The diffuse symmetrical myopathy associated with AZT is thought to be due to the drug's interference with mitochondrial

From the Department of Pathology, LHSC-UC, London, Ontario, Canada. ReCEIVED MARCH 12, 2002. ACCEPTED IN FINAL FORM June 12, 2002. Reprint requests to: Robert R. Hammond, Department of Pathology, LHSC-UC, 339 Windermere Rd., London, Ontario, Canada, N6A 5C1 
Figure 1:

a) Inflammatory myopathy with increased fibre size variation and mononuclear endomysial infiltrates (arrows), Hematoxylin-Phloxine-Saffron (HPS), bar $=100 \mu \mathrm{m}$.

b) Ragged-red fibres (arrows), Gomori trichrome, bar $=100 \mu \mathrm{m}$.

c) Ragged-red equivalent fibres (arrows) (enzymatic discordance), succinic acid dehydrogenase $(S D H)$, bar $=100 \mu \mathrm{m}$.

d) Mitochondrial and cristal pleomorphism and atypia, Electron microscopy, bar $=0.5 \mu \mathrm{m}$.

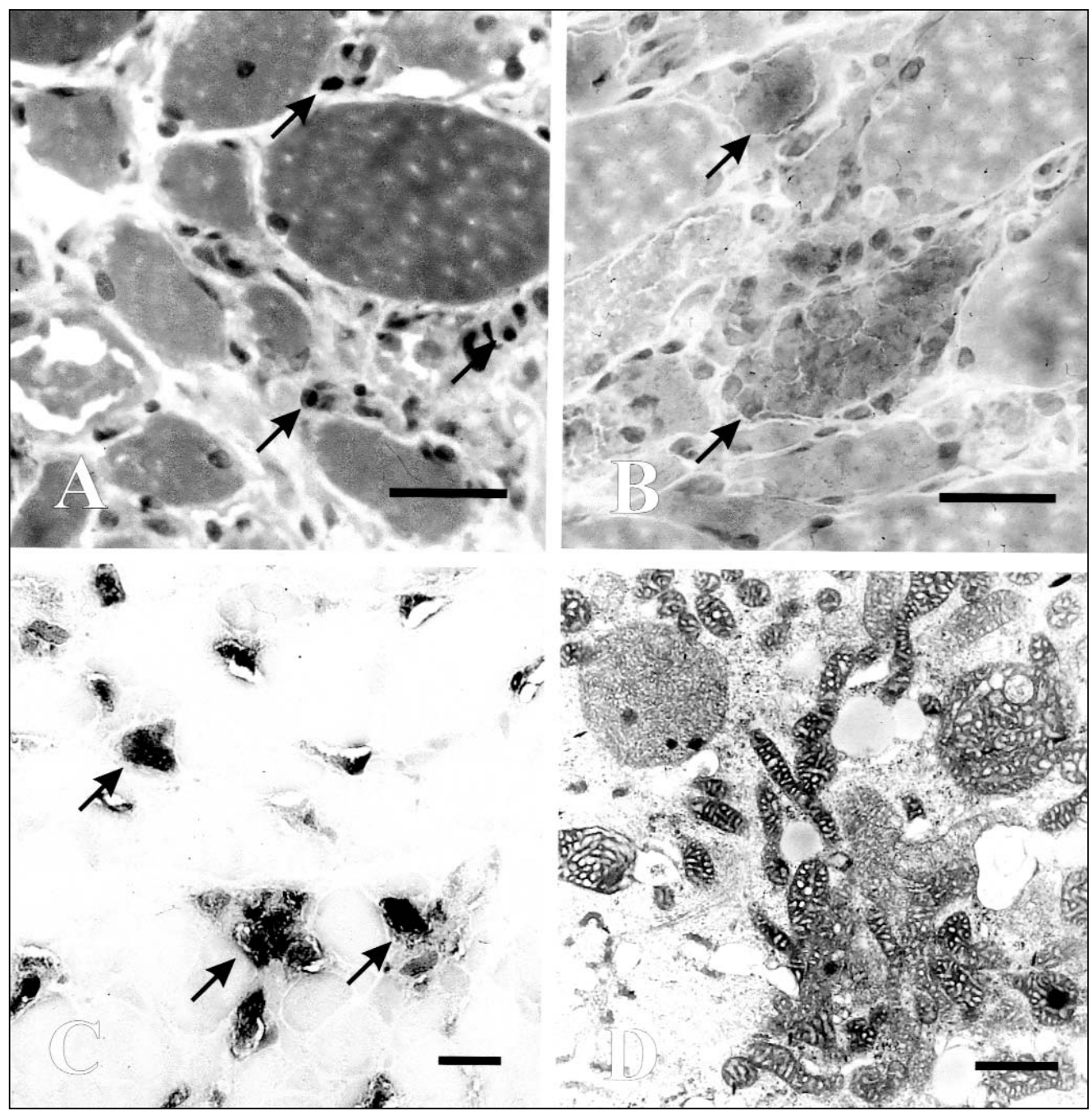

DNA-polymerase function. ${ }^{10}$ The pathological hallmark is the presence of ragged red fibres (RRFs), which signify accumulations of abnormal mitochondria. ${ }^{7}$ Creatine kinase levels may or may not be altered in AZT myopathy. In a large collection of cases, Dalakas et $\mathrm{al}^{9}$ proposed that mononuclear inflammatory infiltrates could be ascribed to AZT and not necessarily represent concurrent polymyositis.

We report the additional case of a 52-year-old HIV-1 positive male presenting with progressive muscle weakness. His initial biopsy identified HIV-1 polymyositis and AZT myopathy. Six months after stopping AZT and beginning corticosteroids, a repeat biopsy confirmed that both pathologies had resolved. Few cases have been reported in which a second biopsy was performed after discontinuing AZT to demonstrate the resolution of pathological findings. This case again raises the issue of whether or not such instances represent one pathological process or two and whether or not corticosteroids are necessary.

\section{Clinical history}

A 52-year-old male developed slowly progressive proximal muscle weakness of his arms and legs beginning in September of 1999. He was known to be HIV-1 positive since 1996, which was acquired through unprotected intravenous drug use. He was treated with 200mg of AZT twice daily in 1996. He had a remote history of hepatitis C which was inactive, a positive tuberculin skin test in 1998, with an abnormal chest $\mathrm{x}$-ray showing small granulomas in his right lung base, in addition to granulomatous calcifications in his right hilum and mediastinum. He received a course of isoniazid and pyridoxine beginning July of 1999.

He began to complain of myalgias in his thighs and calves with occasional burning pain in his feet and palms in the fall of 1999. This was accompanied by weakness in his lower extremities, which progressed to involve his upper extremities and facial muscles over the next several months.

By January of 2000, he was unable to climb stairs and had difficulty sitting up in bed. There was mild weakness of his peri-ocular and peri-oral 
Figure 2:

a) Fibre size variation (bimodal) without inflammation, HPS, bar $=100$ um.

b) Resolution of ragged-red fibres, Gomori trichrome, bar $=100 \mu \mathrm{m}$.

c) Resolution of ragged-red equivalent fibres (enzymatic discordance). A few very atrophic fibres showed increased SDH staining (arrows) but preserved cytochrome oxidase (COX) expression and normalized mitochondrial ultrastructure, $\mathrm{SDH}$, bar $=100 \mu \mathrm{m}$.

d) Selective type II fibre atrophy (darkly stained fibres are type II). ATPase at $\mathrm{pH} 9.4$, bar $=100 \mu \mathrm{m}$.

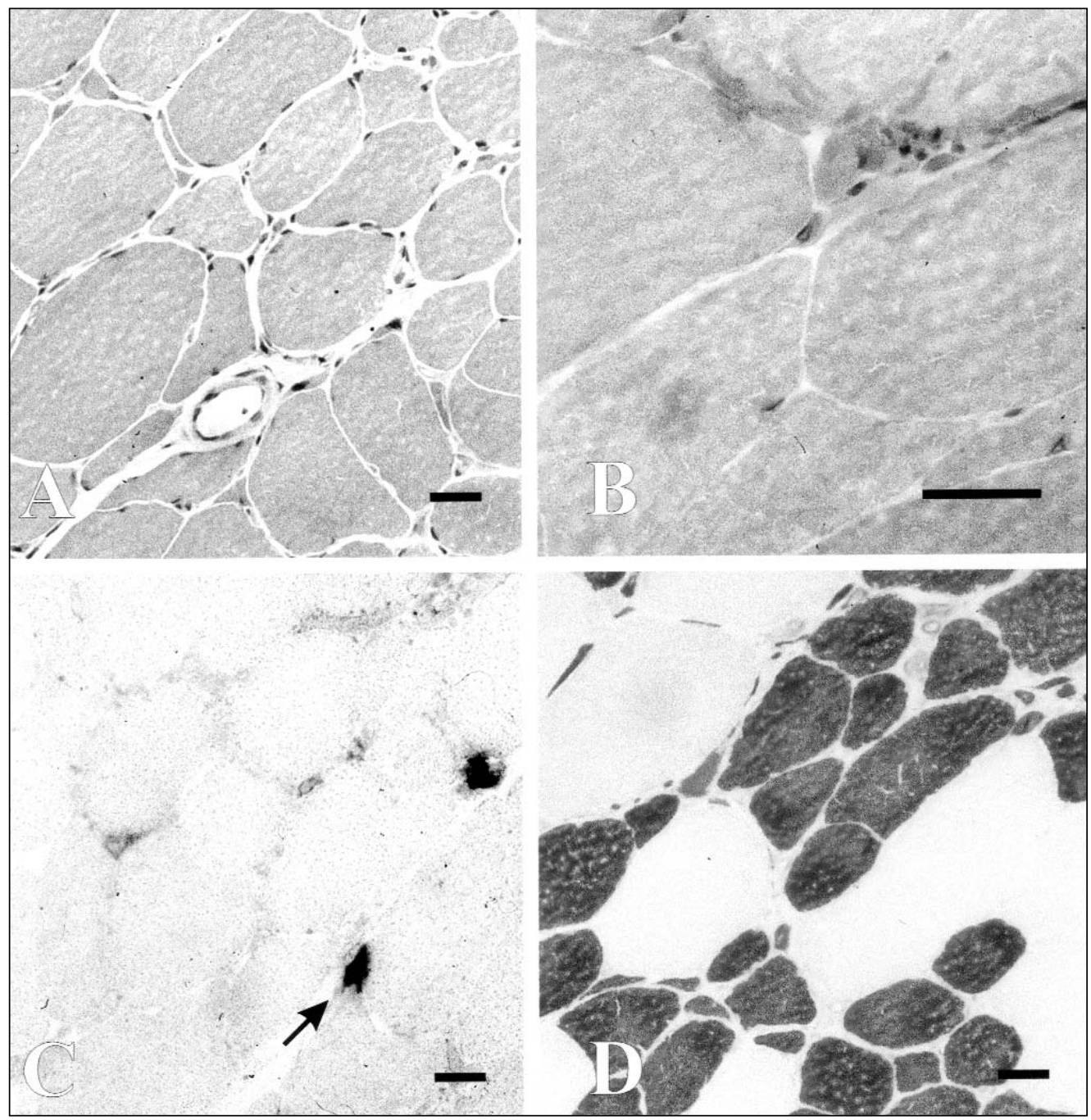

muscles, mild neck flexor weakness, and proximal greater than distal weakness of his arms and legs in a symmetrical fashion. Power was graded at MRC grade 4/5 in his arms, grade 3/5 in his hip flexors, quadriceps and hamstrings, and grade 4 elsewhere in his legs. Deep tendon reflexes were grade 2 in his arms and absent in his lower extremities.

Medications included AZT 200mg BID, ritonivir 400mg BID, indinavir 400mg BID, naproxen 250mg TID, 3TC 150mg BID, pyridoxine $25 \mathrm{mg} \mathrm{OD}$, isoniazid $300 \mathrm{mg} \mathrm{OD}$, and ranitidine $150 \mathrm{mg}$ BID.

Laboratory investigations upon admission revealed that his CD4 count was moderately decreased at 330 cells $/ \mathrm{mm}^{3}$ with an HIV-1 viral load of 11403. His CK level was 66 (normal range 38-174) U/L.

Electromyography revealed some large amplitude motor units in his right quadriceps and gluteus medius with decreased recruitment, but no fibrillations or positive sharp waves. Electromyogram studies of his right tibialis anterior, psoas, gastrocnemius, deltoid, biceps, triceps, brachioradialis and first dorsal interosseus muscles were normal. Motor and sensory nerve conductions in his right arm and leg were within normal limits.
His AZT was discontinued. A muscle biopsy was performed which revealed an inflammatory myopathy with endomysial and perimysial mononuclear infiltrates (Figure 1a). Partially invaded muscle fibres were present, as well as degenerating fibres. Many fibres showed basophillic subsarcolemmal accumulations and ragged red pathology on Gomori preparations (Figure 1b). Histochemical staining for cytochrome oxidase (COX), and succinic acid dehydrogenase (SDH) displayed numerous examples of enzymatic discordance (ragged red fibre equivalents) affecting approximately $25 \%$ of fibres, especially the type I subpopulation (Figure 1c). Ultrastructural examination revealed large accumulations of atypical mitochondria within muscle fibres. The mitochondria were enlarged, misshapen and contained unusual redundant cristae (Figure 1d). Many of the abnormal mitochondria also contained irregular dense accumulations of granular osmiophilic material. Paracrystalline inclusions were not seen. Excessive lipid and focal collections of Z-band material (nemaline rod-like deposits) were also noted, particularly in severely affected fibres.

The patient was subsequently started on $100 \mathrm{mg}$ of prednisone OD for 
one month, which resulted in improved strength by March of 2000 . He was able to ambulate with a walker with at least grade 4 power in all muscle groups.

His strength continued to improve and a second muscle biopsy was performed (six months after the first biopsy) showing resolution of the inflammatory myopathy (Figure 2a) and ragged red fibre pathology (Figures $2 \mathrm{~b}$ and $2 \mathrm{c}$ ). Selective type II fibre atrophy was noted, and this was felt to be secondary to his corticosteroid use (Figure 2d). Occasional atrophic fibres were hyperstaining on NADH and SDH preparations, but were not COX negative nor did they reveal mitochondrial abnormalities by electron microscopy.

\section{Discussion}

HIV-1 polymyositis and AZT myopathy are well-recognized forms of muscle disease among HIV-1 positive patients. While isolated HIV-1 polymyositis usually responds to corticosteroids, AZT myopathy is typically reversed by discontinuation of the drug.

Inflammatory infiltrates indistinguishable from those seen in HIV-1 polymyositis have been reported in association with AZT myopathy ${ }^{9}$ leading to speculation about the relationship between the two pathological findings. In the largest reported series, Dalakas et al concluded that AZT may cause both myositis as well as mitochondrial pathology on the basis of a collection of 20 cases of myopathy in HIV-1 positive patients, 15 of whom had received AZT. In the series, all cases (whether taking AZT or not) had evidence of inflammation on muscle biopsy. Of six patients from the AZT group who were treated with prednisone alone, four showed improvement. Of 12 patients from the AZT group who had their AZT reduced or discontinued, eight showed improvement, one had a reduced $\mathrm{CK}$ and three were unchanged or worse. The authors suggested that AZT may induce a range of pathologies in different individuals, including a variable degree of inflammation. However, given the clinical experience to date and the lack of a controlled trial, the possibility remains that polymyositis and AZT myopathy may coexist in some individuals at least. Indeed, perhaps polymyositis has an unmasking effect on susceptibility to AZT mitochondrial toxicity to explain their frequent coexistence and variable subsequent response to therapy.

This case provides another opportunity to consider the pathogenesis of these two important pathological findings that may arise in such patients; inflammation and mitochondriopathy. In our case, clinical judgement and consultation led to treatment of both afflictions simultaneously on the presumption that polymyositis was coexistent with AZT myopathy. Our patient did well. Unfortunately, as with previous cases, we are left unable to draw definitive conclusions as to whether this represented one disease or two.

Zidovudine myopathy may simply have a spectrum of pathology with respect to inflammatory features as previously suggested, or the pathological features of inflammation and mitochondriopathy may represent separate mechanisms of disease. On the basis of current evidence, the two entities are not necessarily mutually exclusive. This dilemma requires the scrutiny of a prospective randomized clinical trial to clarify the mechanism of disease and to address the appropriateness of corticosteroid therapy in such patients for whom this poses a number of additional risks.

\section{ACKNOWLEDGMents}

The authors thank Dr. George Karpati for helpful consultation and advice. We also thank Deb Reade, June Janzen, and Debbie Newman for their technical expertise. RH was supported by the Ontario HIV Treatment Network.

\section{REFERENCES}

1. Kaul M, Garden GA, Lipton SA. Pathways to neuronal injury and apoptosis in HIV-associated dementia. Nature 2001; 410(6831): 988-994.

2. McArthur JC, Hoover DR, Bacellar H, et al. Dementia in AIDS patients: incidence and risk factors. Multicenter AIDS Cohort Study. Neurology 1993; 43(11): 2245-2252.

3. Chaunu MP, Ratinahirana H, Raphael M, et al. The spectrum of changes on 20 nerve biopsies in patients with HIV infection. Muscle Nerve 1989; 12(6): 452-459.

4. de la Monte SM, Gabuzda DH, Ho DD, et al. Peripheral neuropathy in the acquired immunodeficiency syndrome. Ann Neurol 1988; 23(5): 485-492.

5. Snider WD, Simpson DM, Nielsen S, et al. Neurological complications of acquired immune deficiency syndrome: analysis of 50 patients. Ann Neurol 1983; 14(4): 403-418.

6. Dalakas MC. Retrovirus-Related Muscle Diseases. In: Engel AG, Franzini-Armstrong C, (eds). Myology: basic and clinical. 2nd ed. New York: McGraw Hill, 1994: 1399-1418.

7. Brinkman K, ter Hofstede HJ, Burger DM, Smeitink JA, Koopmans PP. Adverse effects of reverse transcriptase inhibitors: mitochondrial toxicity as common pathway. AIDS 1998; 12(14): 1735-1744.

8. Dalakas MC, Pezeshkpour GH, Gravell M, Sever JL. Polymyositis associated with AIDS retrovirus. JAMA 1986; 256(17): 23812383.

9. Dalakas MC, Illa I, Pezeshkpour GH, et al. Mitochondrial myopathy caused by long-term zidovudine therapy. N Engl J Med 1990; 322(16): 1098-1105.

10. Gherardi RK. Skeletal muscle involvement in HIV-infected patients. Neuropathol Appl Neurobiol 1994; 20(3): 232-237.

11. Illa I, Nath A, Dalakas M. Immunocytochemical and virological characteristics of HIV-associated inflammatory myopathies: similarities with seronegative polymyositis. Ann Neurol 1991; 29(5): 474-481.

12. Marcum J. HIV infection presenting as polymyositis. Del Med J 1995; 67(3): 185.

13. Moyle G. Toxicity of antiretroviral nucleoside and nucleotide analogues: is mitochondrial toxicity the only mechanism? Drug Saf 2000; 23(6 ): 467-481.

14. Sellier P, Monsuez JJ, Evans J, et al. Human immunodeficiency virus-associated polymyositis during immune restoration with combination antiretroviral therapy. Am J Med 2000; 109 (6 ): 510-512.

15. Steinbach LS, Tehranzadeh J, Fleckenstein JL, Vanarthos WJ, Pais MJ. Human immunodeficiency virus infection: musculoskeletal manifestations. Radiology 1993; 186(3): 833-838.

16. White AJ. Mitochondrial toxicity and HIV therapy. Sex Transm Infect 2001; 77(3): 158-173. 